\title{
La tensión entre la libertad de emitir opinión y la de informar y la honra de las personas: importancia y límites de la exceptio veritatis
}

\author{
John Charney*
}

\section{RESUMEN}

Este artículo examina la tensión entre la libertad de emitir opinión y la de informar y la protección a la honra de las personas. Su principal premisa es que un sistema que sanciona penalmente las injurias y calumnias debe ofrecer defensas adecuadas a los imputados por estos delitos. Por ello, el artículo analiza esta tensión a partir de la exceptio veritatis, la principal excepción que nuestro ordenamiento reconoce a imputados por estos delitos. El propósito es comprobar si esta excepción, tal como está formulada, garantiza adecuadamente la libre circulación de información de serio interés público. A partir de un análisis del contenido, alcance y función de la exceptio veritatis en nuestro ordenamiento y en sistemas comparados, el artículo llega a la conclusión que dicha excepción es insuficiente para garantizar adecuadamente esta libertad.

Libertad de emitir opinión e informar - protección a la honra - exceptio veritatis

\section{The tensions between free speech and the protection to one's reputation: importance and limits of the exceptio veritatis}

\begin{abstract}
AbTract
This article examines the tensions between freedom of speech and the protection of one's reputation. Its main assumption is that a defendant in criminal libel procedures requires strong defenses. Thus, the article analyses the exceptio veritatis, which is the main defense in Chilean criminal libel law. The purpose is to explore if this defense, as it is, guarantees the free circulation of information of public interest, a basic requirement in any democratic system. After exploring the content, scope and function of the exceptio veritatis in the Chilean and other systems, the article concludes that this defense is not a sufficient guarantee of free speech.
\end{abstract}

Freedom of speech - reputation - exceptio veritatis

* Doctor en Derecho, King's College de Londres, Reino Unido. Profesor de Derecho Constitucional Pontificia Universidad Católica de Valparaíso. Correo electrónico: john.charney@ucv.cl.

Artículo recibido el 22 de julio de 2015 y aceptado para su publicación el 30 de agosto de 2016. 


\section{INTRODUCCIÓN}

E n su célebre ensayo "Sobre la libertad", J.S. Mill aplaude el hecho que -a mediados del siglo XIX- ya no sea necesario elaborar nuevos argumentos para demostrar que la libertad de prensa es un mecanismo fundamental para garantizar un buen gobierno. Estos argumentos han sido prolíficos y brillantemente articulados -nos recuerda-. Por lo mismo, considera que sería extraño que en Inglaterra un gobierno intentara limitar una libertad cuya conquista parecía completamente lograda ${ }^{1}$. Es por esta razón que antes de embarcarse en una nueva discusión respecto del tema, Mill comienza pidiendo disculpas a aquellos lectores que no encontrarán nada nuevo en sus palabras. Tratándose de la discusión acerca de las tensiones entre la libertad de opinión y de informar, por una parte, y el derecho a la honra, por la otra, podría ser aconsejable seguir el gesto de Mill. En efecto, bastante se ha discutido en nuestro país al respecto como para aventurarse en una discusión más ${ }^{2}$.

Una de las discusiones fundamentales que se ha dado es la de la proporcionalidad de la sanción penal como medida de protección de la honra. ¿Son estas sanciones proporcionales con el legítimo fin que buscan satisfacer? ¿No constituirían una limitación inaceptable a la libertad de informar y opinar? ¿Son -finalmente- necesarias en un sistema democrático? Bastante se ha escrito en nuestro país en torno a estas preguntas ${ }^{3}$. Sin embargo, a pesar de su relevancia, muy poco o nada se ha dicho concerniente a las excepciones judiciales con que cuenta el imputado en estos juicios en nuestro sistema jurídico. Este artículo explorará esto último. Lo hará partiendo de la base de que un sistema que criminaliza las injurias y calumnias y que no es capaz de ofrecer defensas adecuadas al imputado por esos delitos, pone un serio obstáculo a la libertad de expresión. Esto es particularmente grave cuando alcanza -como sucede en Chile- al discurso político, ya que la protección de este tipo de discurso es fundamental para la vitalidad de un sistema democrático. Así lo han sostenido, por lo demás, un conjunto de autores que entienden que la protección que un orden constitucional debe dar al discurso político se justifica en que este es un elemento esencial del autogobierno colectivo ${ }^{4}$, refuerza la autonomía

${ }^{1}$ Las predicciones de Mill fueron incorrectas, ya que poco tiempo después de la publicación del ensayo, ocurrieron las persecuciones gubernamentales de la prensa de 1858. Ver Mill, J.S., On liberty, Cosimo Classics, Londres, 2005 , pp. 19-20.

${ }^{2}$ Ver Cea, J.L., "Los derechos a la intimidad y a la honra en Chile”, en Ius et Praxis, vol. 6, núm. 2, 2000, pp. 153-159; Nogueira, H. , "Pautas para superar las tensiones entre los derechos a la libertad de opinión e información y los derechos a la honra y la vida privada", en Revista de Derecho Universidad Austral de Chile, vol. XVII, pp. 139-160; Fuentes, M.F., "El derecho a la honra como límite a la libertad de información hasta el momento de la acusación penal", en Revista de Derecho de la PUCV, vol. XXXVII, pp. 547-564.

${ }^{3}$ Ver, en especial, Peña, C., "Informe sobre el proyecto de ley de protección del honor y la intimidad de las personas", en Cuadernos de Análisis Jurídicos, Colección Derecho Privado, vol. 1, pp. 75-104, disponible en http://www.udp.cl/descargas/facultades_carreras/derecho/pdf/investigaciones/Cuadernos_de_analisis_ Coleccion_Derecho_Privado/numero1/informe_proyectoley_carlospena.PDF.

${ }^{4}$ Ver, en general, Meiklejohn, Alexander. "Free Speech and Its Relation to Self-Government", en Political Freedom: The Constitutional Powers of the People, Oxford University Press, New York, 1965. 
política de los individuos 5 y la participación de los ciudadanos en las transformaciones políticas, culturales y sociales de un país ${ }^{6}$.

El análisis de las defensas judiciales se centrará en la excepción de la verdad o exceptio veritatis. Esta es la que permite a un imputado defenderse de una querella de injurias o calumnias probando la verdad de sus dichos y es la principal excepción que nuestro ordenamiento reconoce en esta materia. El análisis se abordará desde dos perspectivas. La primera de ellas examina la suficiencia interna de la exceptio veritatis (segunda sección). Esto consiste en identificar si el ámbito de aplicación de la excepción, es decir, las circunstancias bajo las cuales un imputado puede defenderse de una querella en su contra, probando la verdad de sus dichos, es adecuado (o suficiente) para las exigencias de un sistema democrático. La segunda explora la suficiencia externa de la exceptio veritatis (tercera sección). Aquí se analizará si un sistema que reconoce la exceptio veritatis como única o principal excepción en materia de injurias y calumnias es capaz de garantizar adecuadamente la libre circulación de ideas e información de interés público o si, por el contrario, produce un efecto silenciador o intimidador en la prensa y en la crítica en general. En esta parte nos apoyaremos en la experiencia comparada, principalmente la del mundo anglosajón, que ha avanzado bastante en este punto. Antes de comenzar el análisis de la exceptio veritatis, propiamente tal, analizaremos a continuación algunos de los problemas asociados a la criminalización de las injurias y calumnias.

\section{LOS OBSTÁCULOS DE LA CRIMINALIZACIÓN DE LAS INJURIAS Y CALUMNIAS}

La protección a la reputación y a la honra de las personas es fundamental para preservar su dignidad. Como dijo Shakespeare, "en el hombre y en la mujer el buen nombre es la joya más inmediata de sus almas”. Por eso -agrega- quien ha perdido la honra ha perdido la parte inmortal de su ser y solo le queda la parte animal ${ }^{7}$. Resguardar la honra de las personas también es importante para el correcto funcionamiento de un sistema democrático. En efecto, en la medida en que el debate y la discusión pública se construyen sobre la base de argumentos y razones y no a base de descalificaciones personales, mejora el nivel de la deliberación y con ello la calidad de nuestras democracias ${ }^{8}$. Por estos motivos, a lo ancho del mundo y a lo largo de la historia se han diseñado leyes tendientes a garantizar la debida protección que la honra y la reputación de las personas merecen 9 .

\footnotetext{
${ }^{5}$ Post, Robert, "Participatory Democracy and Free Speech", Virginia Law Review 97, 2011, 477.

${ }^{6}$ Baker, C. Edwin. Human Liberty and Freedom of Speech. Oxford University Press, New York, 1993, pp. 47-48.

${ }^{7}$ Shakespeare, W., Otelo, Ed. Andrés Bello, Santiago, 1998, p. 73.

${ }^{8}$ Ver Gutmann, A. \& Thompson, D., Why deliberative democracy? Princeton University Press, New Jersey, 2004, ch. 1.

${ }^{9}$ Para una defensa más extendida al derecho a la honra en Chile ver Cea, J.L., "Derecho a la intimidad y a la honra en Chile", Ius et Praxis, 6 (1), 2000.
} 
Ahora bien, en la medida en que aumenta la protección a la honra, disminuye necesariamente la libertad de emitir opiniones, de expresarse abiertamente en la esfera pública y el poder de la prensa de vigilar y controlar las acciones del gobierno y de las autoridades políticas ${ }^{10}$. En efecto, si las sanciones asociadas a los delitos contra el honor (en especial cuando se dirigen en contra de autoridades públicas) son muy gravosas, entonces se corre el riesgo de silenciar la crítica política y el control que los medios de prensa deben ejercer sobre sus gobernantes. Es por ello que un sistema legal que protege celosamente la honra de las personas tendrá un déficit en la protección de la libertad de prensa, tal como un sistema que defienda sin miramientos esta última quedará al debe en la protección de la primera. El desafío consiste entonces en encontrar un equilibrio, un punto medio que permita una adecuada protección a la reputación sin atentar indebidamente contra la libertad de expresión, una de las garantías fundamentales de un sistema democrático. Para ello es fundamental revisar el tipo de sanciones asociadas a estos delitos.

Nuestro ordenamiento jurídico protege la honra de las personas en diversos cuerpos normativos. La Constitución en su artículo $19 \mathrm{~N}^{\circ} 4$ asegura: "El respeto y protección a la vida privada y a la honra de la persona y su familia”. Esta disposición, hasta la reforma constitucional del 2005, incluía en su inciso segundo la figura de difamación criminal, agregada al texto a sugerencia del Consejo de Estado. Su propósito, de acuerdo con el Consejo, fue evitar los abusos de publicidad que, según ellos, habían causado un grave daño al país en el pasado. Las palabras del Consejero Jorge Alessandri, en sesión $60^{a}$ del 26 de diciembre de 1978, ilustran el sentir del Consejo. Según Alessandri, "el concepto de libertad de prensa, tal como emanó de los postulados de la Revolución Francesa, es hoy algo obsoleto y cuya vigencia resulta incompatible con el gobierno de los pueblos y con la tranquilidad pública" ${ }^{11}$. Por esta razón, el Consejo incorporó la difamación al texto constitucional y la redactó en los siguientes términos: "Si la infracción de este precepto se cometiere a través de un medio de comunicación social, y que consistiere en la imputación de un hecho o acto falso, o que cause injustificadamente daño o descrédito a una persona o a su familia será constitutiva de delito y tendrá la sanción que determine la ley”. La Ley No 20.050 derogó el inciso segundo del artículo $19 \mathrm{~N}^{\circ} 4$. El principal argumento para su derogación fue que dicha norma era un grave atentado contra la libertad de expresión. En efecto, los tribunales a partir de ella podían sancionar con penas privativas de libertad a quienes emitieran expresiones que siendo verdaderas, puedan injustificadamente causar daño o descrédito a una persona. Por lo demás, se argumentó que esta disposición constitucional no era necesaria considerando

${ }^{10}$ Esto bajo el supuesto que entendamos la libertad de expresión como una libertad negativa, ver Berlin, I., "Two concepts of liberty”, en Hardy, H. (ed.) Liberty, OUP, Oxford, 2002. Para una versión crítica revisar Zamora, H., "El derecho a la libertad de expresión: ¿Una limitante al poder estatal? (A propósito del diálogo intersubjetivo en una sociedad democrática), Revista de Derecho UCN, vol. 19, núm. $2,2012$.

${ }^{11}$ Ver Historia de la Ley, Constitución Política de la República de Chile, Artículo 19 N 4, Derecho a la Privacidad, p. 59. 
que la protección a la honra de las personas estaba suficientemente protegida por los delitos de injurias y calumnias.

Si bien la derogación del inciso segundo del artículo 19 No 4 de la Constitución fue un avance, aún queda mucho por hacer. Uno de los principales problemas de nuestro ordenamiento jurídico es la criminalización de los “delitos contra el honor". Estos delitos incluyen las injurias y las calumnias y están reguladas en el Título VIII del Libro II del Código Penal y complementadas en la Ley N 19.773 sobre Libertades de Opinión e Información y Ejercicio del Periodismo cuando han sido cometidas por un medio de comunicación social. Las injurias son, conforme al artículo 416 del Código Penal, "toda expresión proferida o acción ejecutada en deshonra, descrédito o menosprecio de otra persona". Las calumnias, por su parte, consisten en "la imputación de un delito determinado pero falso y que pueda actualmente perseguirse de oficio”, de acuerdo con el artículo 413 del mismo Código. Las injurias y calumnias son sancionadas con penas que van desde la reclusión menor en sus grados mínimo a medio y multas que van de seis a once unidades tributarias mensuales y que pueden ascender hasta ciento cincuenta unidades tributarias mensuales cuando hayan sido proferidas por medios de comunicación social.

La criminalización de las injurias y calumnias puede ser una medida eficaz para lograr la protección de la honra de las personas. Sin embargo, es un serio obstáculo al sistema democrático, ya que produce un efecto silenciador en la crítica y el disenso político $^{12}$, afectando la circulación de información de serio interés público ${ }^{13}$. En este sentido, la Comisión Interamericana de Derechos Humanos ha sostenido que la sanción penal "podría conducir un efecto silenciador respecto de todas las personas que estarán sometidas a una constante autocensura antes de denunciar algo que pueda ofender a los más altos funcionarios públicos. Con ello, no solo se podría comprometer la libertad de expresión de las personas condenadas (...) sino de la sociedad en su conjunto" ${ }^{14}$.

Por los problemas que la criminalización de estos delitos produce en un sistema democrático, algunos países, principalmente del mundo anglosajón, o bien los han derogado, trasladando sus sanciones a sede civil, o su persecución ha entrado en franco desuso ${ }^{15}$.

${ }^{12}$ Para un completo análisis acerca del efecto silenciador ver Schauer, F., "Fear, risk and the first amendment: unravelling the chilling effect”, Boston University Law Review, 58, 1978.

${ }^{13}$ Para un análisis cuantitativo en Chile, ver Cabalín, C. y Lagos, C., "Libertad de expresión y periodismo en Chile: presiones y mordazas", Rev. Palabra Clave, vol. 12, núm. 1, 2009, pp. 37-59.

${ }^{14}$ Comisión Interamericana de Derechos Humanos, Resolución 6/2014, Asunto Fernando Alcibíades Villavicencio y otros respecto de Ecuador, párrafo 32.

${ }^{15}$ Es el caso de Inglaterra, que por la vía legislativa derogó la criminalización de todas las formas de injurias contempladas por siglos en el common law. Así, en el 2008 el Parlamento por medio de la sección 79 del Criminal Justice and Immigration Act derogó las injurias blasfemas y en el 2009 derogó las injurias sediciosas, obscenas y difamatorias según consta en la sección 73 del Coroner and Justice Act. Los delitos de injuria, en sus múltiples categorías, fueron derogados por el Parlamento británico a pesar de haber caído en franco desuso por los tribunales durante el siglo XX. Ver Barendt, E., Freedom of speech, OUP, Oxford, 2007, pp. 186. En el caso de Estados Unidos, la gran mayoría de los estados han derogado los delitos de injuria y han traspasado las responsabilidades derivadas de expresiones injuriosas a la esfera del derecho civil, ver Wagner, A. J, \& Fargo, L., "Criminal libel in the United States: A report for the International 
Por su parte, organismos y tribunales internacionales han manifestado consistentemente sus reparos a sanciones desproporcionadas en materias de injurias, tratándose de publicaciones que contengan asuntos de interés público ${ }^{16}$. En el caso Fontevecchia la Comisión Interamericana de Derechos Humanos señaló que estas sanciones "no solo impiden que las personas conozcan informaciones relevantes para el ejercicio de sus derechos, sino que generan un efecto intimidatorio que contradice la obligación del Estado de establecer un marco institucional en el cual el debate sobre todos los asuntos públicos pueda ser abierto, plural, desinhibido y vigoroso" ${ }^{17}$. En el mismo caso, la Corte Interamericana de Derechos Humanos sostuvo que "el temor a una sanción civil desproporcionada puede ser a todas luces tan o más intimidante e inhibidor para el ejercicio de la libertad de expresión que una sanción penal, en tanto tiene la potencialidad de comprometer la vida personal y familiar de quien denuncia o publica información sobre un funcionario público, con el resultado evidente y disvalioso de autocensura, tanto para el afectado como para otros potenciales críticos de la actuación de un servidor público" ${ }^{18}$. En este mismo sentido, la Corte Europea de Derechos Humanos ha señalado frecuentemente que los políticos deben ser más tolerantes frente a la crítica que el resto de los ciudadanos. Por lo mismo, en esa esfera la intensidad de las restricciones a la libertad de expresión debe moderarse ${ }^{19}$.

Independiente de la discusión acerca de la procedencia de la sanción penal, lo cierto es que nuestro ordenamiento jurídico la contempla como salvaguarda del derecho a la honra. Atendida la envergadura de esta sanción, es fundamental analizar si es que el imputado por estos delitos cuenta con los medios adecuados para defenderse. En efecto, si a la gravedad de las sanciones aparejadas a las injurias y calumnias se añade un sistema inadecuado de defensas judiciales, entonces la libertad de expresión queda en una delicada posición que vulnera el balance que un sistema constitucional debe ofrecer al ejercicio y protección de ambos derechos. En especial si las defensas son insuficientes tratándose de expresiones vinculadas a autoridades, políticos y funcionarios públicos respecto de asuntos relativos al ejercicio de sus funciones. Para analizar lo anterior,

Press Institute", By A.Jay Wagner* and Anthony L. Fargo pp. 23-24, disponible en http://www.freemedia. at/fileadmin/resources/application/IPI_Criminal_Libel_in_the_US.pdf.

${ }^{16}$ El Relator Especial sobre la promoción y protección del derecho a la libertad de opinión y expresión de Naciones Unidas recomienda "que solo los casos graves y extremos de incitación al odio se tipifiquen como delitos penales" (Informe del Relator Especial sobre la promoción y protección del derecho a la libertad de opinión y de expresión, NU, Asamblea General, septiembre 2012, párrafo 79). En el mismo sentido, el artículo 10 de la Declaración de Principios sobre Libertad de Expresión de la Comisión Interamericana de Derechos Humanos indica que "La protección a la reputación debe estar garantizada solo mediante sanciones civiles, en los casos en que la persona ofendida sea un funcionario público o persona pública o particular que se haya involucrado voluntariamente en asuntos de interés público”.

${ }^{17}$ Comisión Interamericana de Derechos Humanos, Informe No. 82/10, Caso 12.524, Jorge Fonteveccia y Héctor D’Amico, 13 julio 2010, párrafo 111, disponible en: https://www.cidh.oas.org/demandas/12.524Esp.pdf.

18 Sentencia Corte Interamericana de Derechos Humanos Caso Fonteveccia y D’Amico v. Argentina, 29 de noviembre de 2011. Serie C N 237 , párrafo 74, disponible en: http://www.tc.gob.pe/portal/servicios/ sentenciascidh/seriec_237_esp.pdf.

${ }^{19}$ Lingens v. Austria (1986) 8 EHHR 407; Oberschlick v. Austria (1995) 19 EHHR 389. 
nos enfocaremos en la principal excepción que nuestro ordenamiento reconoce en esta materia: la exceptio veritatis.

\section{LA EXCEPCIÓN DE LA VERDAD Y SUS LÍMITES INTERNOS}

La dogmática penal ha entendido que la honra cubre dos dimensiones o esferas de la vida humana ${ }^{20}$. La primera afecta una dimensión subjetiva que, de acuerdo con Etcheberry, se refiere al sentimiento del honor, es decir, a "la voluntad de reafirmar el propio valer o mérito ante los demás” ${ }^{21}$. La dimensión objetiva, en cambio, está asociada a la percepción que los demás tienen de una persona en particular ${ }^{22}$. Hay quienes afirman que mientras el elemento subjetivo se refiere al honor de una persona; el elemento objetivo se refiere a su honra, sin embargo, ambas expresiones se han utilizado, en general, como sinónimos y es así como las utilizaremos acá ${ }^{23}$. Lo haremos así porque para los efectos de este artículo tales distinciones no son necesarias. Por lo demás, mientras las calumnias protegen la honra en un sentido objetivo, el bien jurídico protegido por los delitos de injuria cubre ambas dimensiones. Mientras las injurias contumeliosas protegen la honra en un sentido subjetivo; las injurias difamatorias protegen la honra en un sentido objetivo ${ }^{24}$.

Debido a la naturaleza del delito de injurias, para lesionar el bien jurídico protegido no es necesario que las afirmaciones injuriosas sean falsas ${ }^{25}$. Por el contrario, ciertas verdades pueden ser muchísimo más perjudiciales para la honra de una persona que cualquier artilugio que respecto de ella se pueda inventar ${ }^{26}$. Esto puede que no sea problemático tratándose de injurias en contra de ciudadanos comunes. El hecho que

${ }^{20}$ Bacigalupo, E., Delitos contra el honor, Hammurabi, Buenos Aires, 2002, p. 68.

${ }^{21}$ Etcheberry, A., Derecho penal: parte especial, Tomo III, Tercera edición, Editorial Jurídica de Chile, Santiago, 2001, p. 152.

22 Ibid.

${ }^{23}$ Sin embargo, hay quienes señalan que mientras el elemento subjetivo se refiere al honor de una persona; el elemento objetivo se refiere a su honra. Ver Forero, J., Los derechos fundamentales y su desarrollo jurisprudencial, Editextos J.U., Bogotá, 1994, pp. 153.

${ }^{24}$ Mientras la expresión "menosprecio" empleada por el Código en el artículo 416 alude a una ofensa al honor en el sentido subjetivo, las expresiones "descrédito" y "deshonra" aluden a la ofensa al honor en el sentido objetivo. Ver Etcheberry, A., Derecho penal: parte especial, Tomo III, Tercera edición, Editorial Jurídica de Chile, Santiago, 2001, pp. 153 y 161.

${ }^{25}$ A diferencia de lo que ocurre con las calumnias en que la falsedad de la imputación es un elemento del tipo penal. Ver ibid, p. 177.

${ }^{26}$ De ahí que la máxima que guiaba la jurisprudencia del tribunal de censura inglés en el siglo XVII y que luego fue absorbida por el common law era la siguiente: the greater the truth, the greater the libel (mientras mayor la verdad, mayor la injuria). Por mucho tiempo las injurias sediciosas en los países anglosajones protegían la reputación de las autoridades sin reconocer la defensa de la verdad a quienes fueran imputados por delitos de injuria. En Inglaterra el reconocimiento legal de la excepción de la verdad fue el producto de una larga lucha por la libertad de prensa. Solo en 1843 se reconoce por ley (Lord Campbell's Act) que la verdad de una declaración es una defensa completa en contra de una acusación de injurias en la medida en que las afirmaciones injuriosas sean de interés público. Ver Wickwar, W.H., The Struggle for the Freedom of the Press, 1819-1832, G. Allen \& Unwin ltd, London, 1928, 19. En Chile, por su parte, las injurias contra la 
Diego (un ciudadano común) sea una persona negligente, no exime de responsabilidad a quien publica abiertamente ese hecho. Sin embargo, las cosas cambian si Diego es un funcionario público, en especial si es negligente en el ejercicio de sus funciones públicas. Una democracia debe proteger las publicaciones que contengan hechos verdaderos cuando estos sean de alto interés público, aun cuando el conocimiento de estos pueda dañar la reputación o la honra de una persona. Si un medio de comunicación dice, por ejemplo, que un alto funcionario de gobierno utiliza negligentemente recursos públicos y no puede defenderse de una querella de injurias probando la verdad de esa afirmación, entonces se lesiona gravemente el derecho a informar, que es un componente esencial de todo sistema democrático ${ }^{27}$.

La exceptio veritatis permite que, en determinadas circunstancias, el querellado pueda ser absuelto cuando logre probar la verdad de sus dichos. Tratándose de calumnias, el artículo 415 del Código Penal indica que "El acusado de calumnia quedará exento de toda pena probando el hecho criminal que hubiere imputado”. De esta forma, respecto de las calumnias, la exceptio veritatis es la regla general: se concede a todo imputado independiente de las circunstancias particulares del caso. Muy distinta es la regla en materia de injurias. El Código Penal chileno, siguiendo al español casi al pie de la letra en este punto, incorpora la excepción de la verdad en su artículo 420. Siguiendo la máxima de que la verdad o falsedad de una afirmación es irrelevante para la configuración del delito de injurias, el artículo 420 establece como regla general que "[al] acusado de injuria no se admitirá prueba sobre la verdad de las imputaciones...". Sin embargo, acto seguido, el mismo artículo concede a modo excepcional -valga la redundancia- la excepción de la verdad. Esta procede, indica el Código, cuando se trata de injurias "dirigidas en contra [de] empleados públicos sobre hechos concernientes al ejercicio de su cargo". Debido a la relevancia de los hechos denunciados en estos casos, la reputación de los empleados públicos cede en beneficio de un interés público real que consiste en el derecho de la sociedad a tomar conocimiento acerca de asuntos que -siendo verdaderos- la afectan (o pueden afectarla) en su conjunto. La pregunta que surge en este punto es si esta excepción debiera concederse solo cuando se trate de injurias dirigidas en contra de empleados públicos concernientes al ejercicio de su cargo. ¿Qué pasa, por ejemplo, con hechos que siendo de alto interés público, no se refieren a empleados públicos o, refiriéndose a ellos, no sean concernientes al ejercicio de su cargo?

La Ley 19.773 sobre Libertades de Opinión e Información y Ejercicio del Periodismo (Ley de Prensa) complementa el artículo 420 del Código Penal. En efecto, tratándose de injurias proferidas por un medio de comunicación social, el artículo 30 de la ley extiende la exceptio veritatis a situaciones en las cuales "la imputación se produjere con motivo de defender un interés público real”. Asimismo enumera algunos hechos, que

autoridad y el desacato o injurias graves contra la autoridad no otorgaban excepción de la verdad a quienes fuesen acusados de su comisión. Estos tipos penales solo fueron derogados el 2005 mediante la Ley 20.048.

${ }^{27}$ Para un análisis detallado acerca del rol fiscalizador de la prensa en un sistema democrático ver Blasi, V., "The checking value in first amendment theory", American Bar Foundation Research Journal, Vol. 3, 1977. 
para los efectos de la procedencia de la excepción, califica como de interés público ${ }^{28}$. De esta manera, el artículo 30 de la Ley de Prensa protege el derecho a la información en un conjunto de situaciones en las que está comprometido el interés público y que no son cubiertas por el artículo 420 del Código Penal. Con ello, refuerza la exceptio veritatis y da un mayor grado de protección a la libertad de los medios de comunicación de informar a la ciudadanía respecto de asuntos de interés público, que de acuerdo con la Corte Interamericana de Derechos Humanos, consisten en "opiniones o informaciones sobre asuntos en los cuales la sociedad tiene un legítimo interés de mantenerse informada, de conocer lo que incide sobre el funcionamiento del Estado, o afecta derechos o intereses generales o le acarrea consecuencias importantes" 29 .

Si bien la exceptio veritatis refuerza la libertad de informar, permitiendo la absolución del imputado en las circunstancias que establece la ley, esta tiene algunas insuficiencias que a continuación exploraremos. Como hemos visto, el artículo 30 de la Ley de Prensa refuerza la excepción de la verdad al ampliar su ámbito de aplicación a ciertas situaciones en las que el interés público se encuentra comprometido. De esta forma, si la publicación calza con alguno de los supuestos contemplados en la norma y el imputado logra probar la verdad de sus dichos, será absuelto de la querella de injuria. Sin embargo, la excepción "ampliada" de la verdad, contenida en la Ley de Prensa, se concede solo al imputado que haya proferido sus dichos por algún medio de comunicación social. De esta manera cuando las injurias sean pronunciadas por medios distintos, se aplica la regla general del artículo 420 del Código Penal, que como ya vimos, solo reconoce la excepción de la verdad respecto de injurias dirigidas en contra de empleados públicos acerca de hechos relativos al ejercicio de sus funciones.

Aquí se produce un vacío legal. En efecto, si en la situación (a) $X$ afirma $y$ en contra de $Z$ en un medio de comunicación social, siendo $y$ un hecho de interés público de acuerdo con el artículo 30 de la ley de prensa, entonces $X$ podrá deducir la exceptio veritatis frente a una querella de injurias interpuesta por $Z$ y será absuelto si logra probar la verdad de sus dichos. Sin embargo, si en la situación (b) $X$ afirma $y$ en contra de $Z$ en la calle a viva voz, no podrá interponer la exceptio veritatis frente a una querella de injurias, salvo que $Z$ sea un funcionario público e $y$ un hecho relativo al ejercicio de sus

\footnotetext{
${ }^{28}$ Según lo dispuesto por el artículo 30 de la Ley 19.773 "se considerarán hechos de interés público de una persona los siguientes:

a) Los referentes al desempeño de funciones públicas;

b) Los realizados en el ejercicio de una profesión u oficio y cuyo conocimiento tenga interés público real;

c) Los que consistieren en actividades a las cuales haya tenido libre acceso el público, a título gratuito u oneroso;

d) Las actuaciones que, con el consentimiento del interesado, hubieren sido captadas o difundidas por algún medio de comunicación social;

e) Los acontecimientos o manifestaciones de que el interesado haya dejado testimonio en registros o archivos públicos, y

f) Los consistentes en la comisión de delitos o participación culpable en los mismos.

${ }^{29}$ Sentencia Corte Interamericana de Derechos Humanos Caso Fonteveccia y D’Amico v. Argentina, 29 de noviembre 2011. Serie C No 237, párrafo 61.
} 
funciones. De esta forma, frente a expresiones idénticas, la ley otorga la excepción de la verdad en la situación (a), pero no en la situación (b). Esto es paradójico. En efecto, una característica esencial de los medios de comunicación es que ellos divulgan, difunden o propagan sus mensajes (cualesquiera sean sus formas y contenidos) al público en general. De este modo, las expresiones transmitidas por estos medios permiten la multiplicación de las audiencias capaces de recibir un determinado mensaje. Por ello, el daño objetivo a la honra de una persona a causa de una expresión injuriosa aumenta considerablemente si esta expresión es proferida por un medio de comunicación social. Esto indica que si la excepción de la verdad ampara expresiones injuriosas transmitidas en los medios de comunicación social, también debiera amparar las mismas expresiones cuando estas no sean enunciadas por estos medios ${ }^{30}$. Por otra parte, el propósito de la excepción de la verdad es permitir que hechos de interés público emerjan en la esfera pública cuando estos hechos sean verdaderos. Lo que se protege es el valor intrínseco de cierta información y por ello su protección debiera ser independiente del medio por el que se propaga.

Un segundo problema de la exceptio veritatis está relacionado con la carga de la prueba. En efecto, según las reglas generales, es el imputado el que debe acreditar la verdad de las expresiones injuriosas. Esto tiene ciertas ventajas, ya que obliga al querellado a verificar la veracidad de sus dichos antes de hacer una publicación que pueda afectar la honra de un tercero. Sin embargo, la prueba de la verdad puede tener un serio efecto disuasivo en la publicación de hechos verdaderos tratándose de asuntos de serio interés público. Tal como lo dijera el juez Brennan en el famoso caso Sullivan v. The New York Times, cuando la carga de la prueba de la verdad recae en el querellado, este tenderá a abstenerse de criticar a la autoridad si no es capaz de probar la veracidad de sus dichos en juicio, aun cuando se trate de hechos de serio interés público y que crea verdaderos e incluso cuando esos hechos sean, en efecto, verdaderos ${ }^{31}$. La intensidad de esta afirmación aumenta en la medida en que las sanciones asociadas a las injurias sean más gravosas. El punto central aquí es que la prueba de la verdad no es fácil para el imputado. Y no lo es precisamente porque en la mayoría de los casos es el querellante quien cuenta con los antecedentes necesarios para acreditarla. La pregunta que surge entonces es ¿qué pasa cuando, por ejemplo, un diario, cuenta con información de serio interés público de un político o autoridad, tiene serios motivos para creer que la información que posee es verdadera, ha hecho una investigación responsable para acreditar su veracidad y, sin embargo, no tiene los medios para probar la verdad? Si el diario decide no publicar esa información, entonces será la opinión pública la que se verá afectada. Por el contrario,

${ }^{30}$ Hay autores que sostienen que tratándose de injurias difamatorias, cuando los hechos denunciados sean de gran trascendencia social se afectaría la antijuricidad material requerida en estos delitos y por tanto sería procedente la exceptio veritatis incluso cuando el artículo 416 no la reconozca. Ver Bullemore, V., \& Mackinnon, J., Lecciones de derecho penal chileno, Tomo III, Santiago, LegalPublishing, 2005, pp. 215 y ss. Para una aplicación de esta tesis en un juicio por injurias proferidas "a viva voz y mediante megáfono al público”, ver Sentencia Juzgado de Garantía de la Ligua, causa RIT 617-2013, Edmundo Pérez Yoma con Rodrigo Mundaca, considerando $5^{\circ}$.

${ }^{31}$ Sullivan v. New York Times, 376 US 254 (1964), p. 279. 
si decide publicar esa información y no logra probar su verdad, el periodista responsable podría sufrir una pena privativa de libertad ${ }^{32}$. Es por este motivo, como veremos en la próxima sección, que la Corte Suprema de Estados Unidos en Sullivan decide restringir las acciones de injurias de autoridades electas solo a aquellas situaciones en que estas han sido víctimas de publicaciones hechas con el propósito malicioso de perjudicarlos. De este modo, es el demandante (el funcionario electo) el que debe probar la mala fe del demandado y no el demandado el que debe probar la verdad de sus dichos ${ }^{33}$.

\section{LAS LIMITACIONES EXTERNAS DE LA EXCEPCIÓN DE LA VERDAD}

El efecto disuasivo de la publicación de asuntos de serio interés público generado por la dificultad probatoria de la verdad nos lleva al análisis de las limitaciones externas de la exceptio veritatis. Este análisis intenta responder a la pregunta pertinente a si la exceptio veritatis es un mecanismo suficiente para garantizar la libertad de información en un sistema democrático. El problema es que si los imputados solo pueden defenderse probando la verdad de sus dichos, dejarán de publicar información cuando no estén seguros de que puedan probarla en juicio. Esto puede ser un serio obstáculo para la democracia cuando se trata de información de serio interés público que haya sido diligentemente recopilada y publicada de buena $\mathrm{fe}^{34}$. La jurisprudencia de los países anglosajones ha avanzado bastante en esta materia. Allí se ha reconocido que la excepción de la verdad no es suficiente para garantizar adecuadamente la libertad de información en un sistema democrático ${ }^{35}$. Para lograr lo anterior es necesario, en determinadas y calificadas circunstancias, excusar la publicación de hechos que puedan ser falsos, aun cuando sean capaces de dañar la honra de una persona. A continuación analizaremos cómo los sistemas estadounidense y británico responden a este problema para concluir con un breve análisis concerniente a las deficiencias de nuestro propio sistema ${ }^{36}$.

${ }^{32}$ Respecto del director del medio, en la medida en que haya obrado diligentemente, no será responsable de las injurias publicadas en su medio, según lo dispone el artículo 39 inciso segundo de la Ley 19.733. Ver sentencia Corte Suprema, causa Rol No 210635-2003 de 23 de enero de 2013, caratulada Rabié con Martorell y otro, considerando undécimo.

33 Sullivan v. New York Times, 376 US 254 (1964), p. 280.

${ }^{34}$ Una revisión de la teoría de la diligente comprobación del ejercicio de la libertad de información se puede encontrar en Nogueira, H. , "Pautas para superar las tensiones entre los derechos a la libertad de opinión e información y los derechos a la honra y la vida privada", en Revista de Derecho Universidad Austral de Chile, vol. XVII, pp. 139-160.

${ }^{35}$ Loveland, I., Political libels: a comparative study, Hart, Oxford-Portland-Oregon, 2000, p. 49.

${ }^{36}$ Es esencial destacar que en Inglaterra este problema fue identificado a comienzos del siglo XIX por el filósofo radical Jeremy Bentham. De acuerdo con Bentham, la verdad debe ser siempre justificada y la falsedad, en determinadas circunstancias, debe ser excusada. Cualesquiera sean los perjuicios que esta medida pueda ocasionar -agrega- serán siempre generosamente sobrepasados por sus beneficios. Ver Bentham, J., "On the liberty of the press", en Bowring, J. (ed.) The works of Jeremy Bentham, William Tait, Edinurgh, 1843, 279. 


\section{The New York Times v. Sullivan}

El caso que marcó un giro radical en esta materia en los Estados Unidos fue The New York Times Co. v. Sullivan. Lester Bruce Sullivan, un comisionado electo de la ciudad de Alabama, interpuso una acción de injurias en contra del New York Times por una solicitada publicada por un grupo de activistas. La solicitada contenía denuncias, algunas de ellas falsas, acerca de violencia policial dirigida en contra de un grupo de estudiantes que participaban en una manifestación del movimiento de derechos civiles. Sullivan consideró que esas imputaciones se dirigían en su contra porque una de sus funciones era la de supervisar las maniobras del departamento de policía. Apoyado en normas federales respecto de injurias sumamente severas que requerían que el demandado probase la verdad de cada una de las imputaciones para ser absuelto, Sullivan obtuvo en primera instancia un fallo a su favor por indemnizaciones ascendentes a US\$500.000. La sentencia fue confirmada por la Corte Suprema de Alabama ${ }^{37}$.

La Corte Suprema de Estados Unidos consideró que las normas relativas a injurias del Estado de Alabama representaban una seria amenaza a la difusión de información políticamente relevante. De acuerdo con la Corte, la prueba de la verdad disuade a los medios de comunicación de publicar asuntos políticamente relevantes, ya que los expone a indemnizaciones millonarias si no son capaces de probar la verdad de sus afirmaciones $^{38}$. Además, el fallo indica que por la dificultad probatoria de la verdad, los medios de comunicación se abstendrán de publicar información de interés público que sea verdadera cuando sean incapaces de probar su verdad en juicio. De esta forma, la prueba de la verdad no puede ser la medida que determine la procedencia de sanciones tratándose de expresiones políticas que puedan afectar la honra de una autoridad. De ser así, la capacidad de control de la prensa de las acciones de los gobernantes se ve severamente limitada. En determinadas circunstancias será necesario tolerar discursos falsos, si lo que se quiere es un debate público robusto. De esta forma, y considerando la naturaleza de la información en juego, la Corte llegó a la conclusión de que las normas atinentes a injurias del Estado de Alabama impiden la existencia de una prensa vigorosa, capaz de controlar y fiscalizar adecuadamente los actos del gobierno ${ }^{39}$. Por esta razón la Corte consideró que estas normas son contrarias a la primera enmienda y las declaró inconstitucionales. A cambio, Sullivan estableció que para que un funcionario electo pudiese obtener una indemnización de perjuicios por expresiones injuriosas relativas al ejercicio

\footnotetext{
37 Sullivan v. New York Times, 376 US 254 (1964), p. 268-278.

38 Ibid., p. 280.
}

${ }^{39}$ De ahí la tesis de V. Blasi que la justificación central de la protección que otorga la primera enmienda de la constitución norteamericana tiene su explicación en la función de control que la prensa ejerce respecto del gobierno. El control de la prensa sería fundamental, según él, para empoderar a la ciudadanía frente a potenciales abusos de la autoridad en el ejercicio de sus funciones y para fomentar la correcta administración de los recursos públicos. La prensa no solo permite, según Blasi, la acción correctiva en contra de potenciales actos de corrupción de la autoridad; además, el control de la prensa incrementa las posibilidades de que tales actos no se vuelvan a cometer en el futuro. Ver Blasi, V., "The checking value in first amendment theory", American Bar Foundation Research Journal, Vol. 3, 1977. 
de su cargo es necesario que estas hayan sido proferidas de mala fe, esto es, cuando el demandado tenga conocimiento de que la información publicada es falsa o bien cuando teniendo dudas acerca de su veracidad, no tome las medidas necesarias para verificarla ${ }^{40}$. Como lo indica I. Loveland, Sullivan establece que las expresiones falsas son un ingrediente inevitable de un debate político potente ${ }^{41}$. En otras palabras, la diseminación de discursos falsos mediante un sistema que reduzca las ventajas judiciales del injuriado es un mal constitucional menor que el de suprimir los discursos verdaderos mediante un sistema de injurias que ponga la balanza a favor del injuriado ${ }^{42}$.

El sistema norteamericano lleva al extremo la protección de la primera enmienda por sobre la honra de los políticos. La Corte Suprema estableció que la primera enmienda protege la publicación o difusión de cualquier información relativa a las funciones de una autoridad electa con independencia de si esta información es verdadera o falsa, en la medida en que no sea el producto de la mala fe de quien las emite ${ }^{43}$. En pocas palabras, la Corte dio carta blanca a todo tipo de discurso político dando a la prensa atribuciones que le permiten desempeñar sus funciones fiscalizadoras sin ningún tipo de inhibición ${ }^{44}$. De esta forma la prensa puede ser un verdadero guardián de los actos de gobierno y con ello contribuir, como sostienen algunos, a la legitimidad del sistema democrático ${ }^{45}$. A pesar de lo anterior, el sistema norteamericano puede traicionar sus propios propósitos. Si la libertad con la que cuentan los medios de comunicación para publicar información de carácter político es casi ilimitada, la calidad del debate en la esfera pública puede verse gravemente afectada. Siguiendo la metáfora que propone Loveland a partir de Sullivan, los discursos falsos podrían -bajo estas circunstancias- transformarse en el ingrediente principal del debate público ${ }^{46}$. Y si la legitimidad de un sistema democrático depende de que la población esté debidamente informada y no completamente desinformada, Sullivan puede ser un elemento corrosivo de esa legitimidad.

\section{Reynolds $v$. Times Newspapers}

El sistema británico es bastante más cauteloso que su homólogo norteamericano, ya que si bien tolera discursos falsos en la esfera pública, lo hace bajo condiciones muchísimo más restringidas. Solo en la medida en que una expresión eventualmente falsa

\footnotetext{
${ }^{40}$ Esto lleva el nombre de "knowing or reckless falsity test", ver Loveland, I., Political libels: a comparative study, Hart, Oxford-Portland-Oregon, 2000, p. 70.

41 Ibid., p. 69.

42 Ibid.

43 Sullivan v. New York Times, 376 US 254 (1964), p. 280.

${ }^{44}$ En consonancia con la tesis de A. Meiklejohn quien sostiene que la primera enmienda contiene una protección de carácter absoluto del discurso político. Meiklejohn, A., "Free Speech and Its Relation to Self-Government", en Political Freedom: The Constitutional Powers of the People. Oxford University Press, New York, 1965.

45 En especial, ibid. y Blasi, V., "The checking value in first amendment theory", American Bar Foundation Research Journal, Vol. 3, 1977.

${ }^{46}$ Loveland, I., Political libels: a comparative study, Hart, Oxford-Portland-Oregon, 2000, p. 69.
} 
sea el producto de una investigación periodística seria y responsable, puede ser tolerada. Esto es lo que se ha denominado el estándar del periodismo responsable y fue adoptado en el caso Reynolds $v$. Times Newspapers. El caso se refiere a un artículo publicado por The Sunday Times a propósito de la renuncia de Mr. Albert Reynolds a la primera magistratura irlandesa en 1994. El artículo sugería que Reynolds había engañado deliberadamente al Parlamento mediante el ocultamiento de información relevante acerca de un controversial nombramiento de un ministro de $\operatorname{Corte}^{47}$. El periódico británico no pudo probar la verdad de sus dichos y fue condenado en primera instancia a indemnizar perjuicios. A pesar de lo anterior, la Corte de Apelaciones y los lores -en definitiva- decretaron que en determinadas circunstancias la publicación de información de interés público debe ser protegida, incluso cuando contenga imprecisiones en la relación de los hechos o estos sean derechamente falsos ${ }^{48}$.

El fallo de los lores destaca la importancia que tiene la difusión de información de contenido político en un sistema democrático. Esta permite -indica la sentencia- que los ciudadanos puedan tomar decisiones informadas respecto de sus opciones y posiciones políticas. Además, habilita a los medios de comunicación a desempeñar adecuadamente su función fiscalizadora, vital para asegurar la fortaleza del sistema ${ }^{49}$. A pesar de lo anterior, el fallo concluye -a diferencia de Sullivan- que no es posible establecer una categoría general de protección al discurso político ${ }^{50}$. En primer lugar, dicha solución significaría hacer una distinción entre discurso político y otras materias, que sin ser necesariamente políticas, siguen siendo de serio interés público. Hay otras figuras públicas que, no siendo políticas, ejercen gran influencia en la sociedad y en la formación de la opinión pública, dice el fallo. Extender a ellas la lógica de Sullivan significaría una desprotección desmesurada de la honra de las personas toda vez que ellas no han entrado al juego político propiamente tal ${ }^{51}$. En segundo lugar, la protección general del discurso político reconocida en Sullivan obliga a los representantes democráticamente electos a probar la mala fe del demandado para obtener una indemnización de perjuicios por injurias. Esto haría casi imposible la protección de la honra de los políticos por la dificultad de probar la mala fe en el sistema procesal británico. De esta forma, y de acuerdo con Reynolds, la protección absoluta al discurso político significaría renunciar a la protección de la reputación de los políticos ${ }^{52}$.

Reynolds, a diferencia de Sullivan, busca garantizar una protección adecuada a la honra de las personas, sin por ello sacrificar la publicación de información que sea de valor para el público. Y para identificar el valor de una publicación, Reynolds señala que es necesario atender a las circunstancias materiales de la misma, así como también a su contenido. En pocas palabras, el valor responde a un estándar de publicación asociado

\footnotetext{
${ }^{47}$ Reynolds $v$ Times Newspapers Ltd. and Others, 134 (H.R.L.R. 1999).

48 Ibid., 153.

49 Ibid., 148.

${ }^{50}$ Loveland, I., Political libels: A comparative study, Hart, Oxford-Portland-Oregon, 2000, p. 170.

${ }^{51}$ Reynolds $v$ Times Newspapers Ltd and Others, 134 (H.R.L.R. 1999), 16.

52 Ibid., 149.
} 
al periodismo responsable y para ayudar a identificarlo Reynolds hace un listado de 10 puntos que, tomados como referencias, sirven de guía para los jueces. En ellos menciona la naturaleza de la información, las fuentes utilizadas, los pasos seguidos para obtener la información, la gravedad de los hechos, si el demandante fue contactado y si la historia contiene su versión de los hechos, entre otras ${ }^{53}$. Si analizadas en su conjunto, estas circunstancias llevan a la conclusión de que la publicación fue el producto de una investigación periodística responsable, el juez debiese protegerla frente a una acción de injurias, aun cuando la publicación contenga imprecisiones o falsedades respecto de los hechos que relata. La defensa de Reynolds permite al demandado defenderse de las injurias probando que cumplió con el estándar del periodismo responsable.

La defensa de Reynolds fue recientemente derogada, sin embargo, fue fundamental para dar forma a la actual defensa de interés público contenida en la sección 4 de la Defamation Act 2013. Esta se aplica cuando se trate: (a) de asuntos de interés público; (b) respecto de los cuales el demandado pueda razonablemente creer que su publicación contribuye al fortalecimiento del interés público. Para determinar lo anterior, el tribunal deberá considerar todas las circunstancias del caso. Tratándose de publicaciones acuciosas e imparciales, será irrelevante si el demandado tomó todos los pasos necesarios para determinar la verdad de los hechos contenido en la publicación. Lo relevante es la forma de la publicación. Tal como en Reynolds, lo que se protege es el periodismo responsable, esto es, el cuidado o celo con el que se organiza la publicación de hechos de interés público.

No hay que desmerecer los efectos políticos asociados a la regulación de las injurias. Del análisis de Sullivan y del sistema británico sería muy pobre decir que mientras el primero ofrece una protección intensa a la libertad de prensa por sobre la reputación de los políticos; el segundo aspira a encontrar un equilibrio entre ambos valores. Bastante más asertivo es indicar que tanto uno como otro son expresiones concretas de lo que debiera ser -y hacer- una democracia. Sullivan ha sido asociado a la idea del autogobierno del pueblo que requiere de una población informada y comprometida con su propio sistema de gobierno ${ }^{54}$. En este sistema la libre circulación de ideas, amparada en una prensa libre, es fundamental. Permite, por una parte, que los ciudadanos tomen decisiones políticas con la mayor cantidad de información posible; por otra, fomenta una comunidad de intereses entre el gobierno y el pueblo que da legitimidad a las acciones del último y al sistema en su conjunto. En efecto, cuando la prensa ejerce un control férreo sobre el gobierno, lo obliga a orientar su acción hacia el bien común y no hacia la defensa de sus propios intereses o de los intereses de algunos sectores de la población. En un sistema democrático como este, la prensa es una piedra angular, mientras que el derecho a la honra ocupa un lugar secundario. A pesar de lo anterior, un sistema como el

\section{Ibid., 153.}

${ }^{54} \mathrm{Al}$ respecto ver Kalven, H., "The New York Times Case: A Note on 'The Central Meaning of the First Amendment'”, The Supreme Court Review, January 1, 1964, p. 209; Bollinger, L.C., The Tolerant Society: Freedom of Speech and Extremist Speech in America, OUP, New York, 1986, p. 49; Powe, L.A., The Fourth Estate and the Constitution: Freedom of the Press in America, University of California Press, Berkeley \& London, 1992, p. 87. 
establecido en Sullivan corre el riesgo de generar los mismos vicios que intenta combatir. En efecto, una prensa desregulada y sin límites puede pasar por alto ciertas prácticas de periodismo responsable que son fundamentales para garantizar un adecuado flujo de la información. Por lo demás, deja de lado la protección a la honra, que un sistema democrático también debe cautelar.

El sistema británico es consciente de los problemas de Sullivan. En efecto, reconoce que la vitalidad del debate político que Sullivan defiende conlleva un relajamiento de los estándares periodísticos, a los que el primero no quiere renunciar. El periodismo responsable es el mecanismo donde se intenta encontrar un punto medio entre la protección de la libertad de expresión, por un lado, y la de la reputación de las personas, por el otro. Este estándar refleja una idea de democracia que valora la deliberación y el debate en la medida en que estos se sometan a ciertas reglas que garanticen su credibilidad.

Defensas de este tipo no solo han sido reconocidas en los sistemas del common law. En España, el artículo 20.7 del Código Penal reconoce el carácter justificante del ejercicio legítimo de un derecho. En este caso los delitos de injuria podrían justificarse cuando sean la consecuencia del legítimo ejercicio de la libertad de expresión y de informar. De acuerdo con la doctrina, para que opere la justificación es necesario, en primer lugar, que exista un interés preponderante en el ejercicio de la libertad de expresión o de información con relación al interés en la protección de la honra ${ }^{55}$. Esto sucede respecto de aquellas expresiones que sean una contribución a la formación de la opinión pública en asuntos de Estado. En segundo lugar, la injuria debe ser necesaria para el ejercicio de la libertad de información. No lo sería si el autor contase con otros medios igual de eficaces para ejercer sus derechos. Finalmente, la justificación requiere que la expresión u opinión no sea manifiestamente injuriosa. Cumpliéndose estos requisitos, el ejercicio del derecho a opinar e informar no dependerá de la plena veracidad de las expresiones injuriosas, sino de las comprobaciones adecuadas que se hayan hecho para verificar la veracidad de la publicación ${ }^{56}$. Como el sistema británico, el español protege publicaciones que sean el producto de una investigación responsable. Algo similar sucede en Alemania y en Austria ${ }^{57}$. A su vez, la Corte Europea de Derechos Humanos ha sostenido en reiteradas ocasiones que es necesario proteger publicaciones que contengan hechos de interés público cuando hayan sido publicados de buena fe, proporcionen información que ha sido recabada de manera responsable y acuciosa y que esté en consonancia con los principios de la ética del periodismo ${ }^{58}$.

\footnotetext{
55 Bacigalupo, E., Delitos contra el honor, Hammurabi, Buenos Aires, 2002, p. 79.

${ }^{56}$ Ibid., p. 81

${ }^{57}$ Ibid., pp. 73-74.

58 Ver en especial, Bladet Tromso v. Norway (2000) 29 EHHR, párrafo 65.
} 


\section{A MODO DE CONCLUSIÓN}

A diferencia de estos sistemas, el nuestro no ofrece una excepción que proteja la publicación de asuntos de serio interés público cuando estos hayan sido el producto de una investigación seria y responsable. Por el contrario, nuestro sistema sanciona las expresiones por el carácter ofensivo de las mismas. El animus injuriandi o el dolo en materia de injurias no es otra cosa, de acuerdo con Etcheberry, que "la conciencia de la aptitud ofensiva de las acciones o expresiones y de que ellas llegarán a conocimiento de terceros o del propio ofendido, según el caso, o la duda acerca de alguna de estas circunstancias, que sin embargo deja indiferente al hechor"59. En este mismo sentido la Corte Suprema ha indicado que "este dolo no solo debe extenderse al sentido de una determinada expresión o acción aislados, sino y muy principalmente, a que tal como en concreto se las proferirá o ejecutará, tienen aptitud para provocar deshonra o menosprecio a la persona a que aluden, y a querer pronunciarlas o expresarlas precisamente de ese modo, cuestión que nada tiene que ver con los supuestos ánimos que trascienden al dolo como son las motivaciones especiales de los autores" 60 .

En consecuencia, el sistema chileno solo requiere conocimiento acerca del carácter ofensivo de la expresión para que se configure el delito de injurias. Esto tiene enormes consecuencias prácticas en cuanto al ámbito de extensión de las injurias. Son injurias, de acuerdo con estas reglas, en primer lugar, todas aquellas expresiones que siendo verdaderas, puedan dañar la honra del demandante. Hemos visto que en determinadas circunstancias, el imputado podrá ser absuelto de responsabilidad penal cuando logre acreditar la verdad de sus dichos. Con todo, tal como vimos en la primera sección, la exceptio veritatis tiene insuficiencias internas. En segundo lugar, serán injurias todas aquellas expresiones que sean falsas, independiente de si el demandante tenía o no conocimiento de su falsedad e independiente de si tomó o no las medidas necesarias para verificar su veracidad. Este segundo punto es crucial, ya que impide una excepción como la de Reynolds o la que reconoce el sistema español. En nuestro ordenamiento la circunstancia de que un imputado por injurias haya recabado la información de manera diligente, tratándose de información de serio interés público y la haya publicado de buena fe es indiferente para determinar su responsabilidad penal. Esto, como vimos, afecta gravemente la libre circulación de información de materias de interés público que un sistema democrático debe garantizar.

Múltiples países han reconocido que la información de interés público que ha sido diligentemente obtenida y publicada de buena fe debe ser protegida aunque dañe la honra de una persona, incluso cuando a la postre se compruebe que dicha información es falsa. Esto es especialmente cierto cuando se trata de sistemas que protegen severamente la honra de las personas, como el nuestro. En efecto, mientras más duras sean las sanciones

59 Etcheberry, A., Derecho penal: parte especial, Tomo III, Tercera edición, Editorial Jurídica de Chile, Santiago, 2001, p. 168.

${ }^{60}$ Sentencia de la Corte Suprema de Justicia, Sala Penal, Rol No 4206-03, de 21 de junio de 2006, considerando $7^{\circ}$. 
mayor será el efecto disuasivo en la publicación de información cuya veracidad no pueda acreditarse o sea muy difícil de acreditar en juicio. A pesar de que el ordenamiento jurídico chileno impone penas privativas de la libertad a las injurias y calumnias, no ofrece defensas judiciales apropiadas a los imputados por estos delitos. Esta combinación no permite un balance adecuado entre el legítimo derecho a la protección de la honra, por un lado, y la libertad de informar, por el otro. Con ello, el sistema de defensas judiciales, tal cual está regulado en nuestro ordenamiento, es un obstáculo para el tipo de debate que un sistema democrático debe ser capaz de garantizar.

\section{BIBLIOGRAFÍA}

Bacigalupo, E., Delitos contra el honor, Hammurabi, Buenos Aires, 2002.

BAKer, C. E., Human Liberty and Freedom of Speech. Oxford University Press, New York, 1993. BARENDT, E., Freedom of speech, OUP, Oxford, 2007.

Bentham, J., "On the liberty of the press", en Bowring, J. (ed.), The works of Jeremy Bentham, William Tait, Edinurgh, 1843.

Berlin, I., "Two concepts of liberty", en Hardy, H. (ed.), Liberty, OUP, Oxford, 2002.

Blasi, V., "The checking value in first amendment theory", American Bar Foundation Research Journal, Vol. 3, 1977.

Bollinger, L.C., The Tolerant Society: Freedom of Speech and Extremist Speech in America, OUP, New York, 1986.

Bullemore, V., \& Mackinnon, J., Lecciones de derecho penal chileno, Tomo III, Santiago, LegalPublishing, 2005.

Cabalín, C. y Lagos, C., "Libertad de expresión y periodismo en Chile: presiones y mordazas", Rev. Palabra Clave, vol. 12, núm. 1, 2009 pp. 37-59.

CEA, J.L., "Los derechos a la intimidad y a la honra en Chile", en Ius et Praxis, vol. 6, núm. 2, 2000, pp. 153-159.

Etcheberry, A., Derecho penal: parte especial, Tomo III, Tercera edición, Editorial Jurídica de Chile, Santiago, 2001.

Forero, J., Los derechos fundamentales y su desarrollo jurisprudencial, Editextos J.U., Bogotá, 1994.

Fuentes, M.F., "El derecho a la honra como límite a la libertad de información hasta el momento de la acusación penal", Revista de Derecho de la PUCV, vol. XXXVII, pp.547-564.

Gutmann, A. \& Thompson, D., Why deliberative democracy?, Princeton University Press, New Jersey, 2004.

Kalven, H., "The New York Times Case: A Note on 'The Central Meaning of the First Amendment"”, The Supreme Court Review, January 1, 1964.

Loveland, I., Political libels: a comparative study, Hart, Oxford-Portland-Oregon, 2000.

Meiklejohn, A., "Free Speech and Its Relation to Self-Government", en Political Freedom: The Constitutional Powers of the People. Oxford University Press, New York, 1965.

Mill, J.S., On liberty, Cosimo Classics, Londres, 2005 , pp. 19-20.

Nogueira, H. , "Pautas para superar las tensiones entre los derechos a la libertad de opinión e información y los derechos a la honra y la vida privada”, en Revista de Derecho Universidad Austral de Chile, vol. XVII, pp. 139-160.

PEÑA, C., "Informe sobre el proyecto de ley de protección del honor y la intimidad de las personas", en Cuadernos de Análisis Jurídicos, Colección Derecho Privado, vol. 1, pp. 75-104.

Post, R., "Participatory Democracy and Free Speech", Virginia Law Review 97, 2011. 
Schauer, F., "Fear, risk and the first amendment: unravelling the chilling effect", Boston University Law Review, 58, 1978.

Powe, L.A., The Fourth Estate and the Constitution: Freedom of the Press in America, University of California Press, Berkeley \& London, 1992.

Shakespeare, W., Otelo, Ed. Andrés Bello, Santiago, 1998.

Wagner, A. J, \& Fargo, L., "Criminal libel in the United States: A report for the International Press Institute” By A.Jay Wagner* and Anthony L. Fargo, pp. 23-24, disponible en http:// www.freemedia.at/fileadmin/resources/application/IPI_Criminal_Libel_in_the_US.pdf

WickWar, W.H., The Struggle for the Freedom of the Press, 1819-1832, G. Allen \& Unwin ltd, London, 1928.

Zamora, H., "El derecho a la libertad de expresión: ¿Una limitante al poder estatal? (A propósito del diálogo intersubjetivo en una sociedad democrática), Revista de Derecho UCN, vol. 19, núm. 2, 2012. 
